\title{
LO TESTIMONIAL Y LA NOVELA-TESTIMONIO
}

\author{
POR \\ ALESSANDRA RICCIO \\ Università di Napoli
}

\begin{abstract}
Cuidado, querido amigo, usted se está saliendo de la historia... Vuelva a leer mi definición: ¡está tan clara! Siendo usted historiador no tiene que meter el pie en ese terreno: es el campo del sociólogo. Tampoco en aquel otro: entraría usted al campo del psicólogo. ¿A la derecha? ¡De ninguna manera! ¡Iría usted a la casa del geógrafo! Y a la izquierda, a la del etnólogo... Pesadillas. Tonterías. Mutilaciones. Abajo los cercos y las etiquetas. El historiador debe trabajar libremente en la frontera, en el deslinde, un pie acá, otro allá. Trabajar útilmente '.
\end{abstract}

En un ensayo a propósito de Marc Bloch y de su Apologie de l'histoire, ou métier d'historien, Lucien Febvre advierte al lector sobre dos cosas significativas: que no piensa poner límites al campo de su investigación y que quiere que su trabajo sea útil. Ambas cosas las había planteado su compañero en el libro escrito como un testamento en el breve tiempo de su encarcelación y antes de ser fusilado por los nazis. La lección de Febvre y Bloch nos enseña que la interdisciplina y lo útil pueden producir resultados tan fructíferos, como ha sido toda la labor de «Les Annales» para enriquecer nuestro conocimiento.

Hablando de «novela-testimonio» muchos años después, Miguel Barnet, responsable de aquella definición, aclara:

Igual leo un libro de Rupert Lewis, Ricardo Pozas y Lévi-Strauss que una novela de Julien Green o García Márquez. No me pongo orejeras ni escafandras. Nosotros, los latinoamericanos, no tenemos todavía una codificación de nuestra cultura como la tienen los países de Europa, como

\footnotetext{
' Lucien Febvre, Problemi di metodo storico (Turín: 1966), p. 174. La traducción es mía.
} 
Francia; estamos siempre en fase de descubrimiento, y no podemos desdeñar ninguna influencia. El escritor latinoamericano que no tenga una formación sociológica y etnográfica de su realidad - al menos intuitiva - es un escritor sietemesino, un escritor a medias; no queda más remedio que ser un poco historiadores de nuestras vidas ${ }^{2}$.

Y Reynaldo González, en una entrevista, frente a la insistente pregunta sobre por qué él y sus congéneres se consideran novelistas y no sociólogos, historiadores, etc., contesta:

Nosotros consideramos que estas ciencias están reservadas a los especialistas y que la proyección de la «ficción» es mucho más amplia y de mayor alcance. Al asumir la definición de novelistas adquirimos una mayor libertad de maniobra frente a una realidad múltiple, pues nuestros informantes hablan a partir de su propia subjetividad y los documentos se redactan a partir de los intereses vigentes; la suma de estas parcialidades exige una libertad formal que la historia no permite. Para mí, hablar de novela-testimonio significa hablar de cómo se mete en la página el material de que disponemos. Por otra parte, no hay ninguna duda de que La fiesta de los tiburones no hubiera tenido 30.000 lectores si hubiera sido un texto histórico-sociológico ${ }^{3}$.

Si mal no lo entiendo, Reynaldo González está reivindicando la libertad de agredir la realidad que le interesa representar amparado por la ambigua sombrilla de la ficción, bajo cuya sombra impalpable puede montar su obra con sorna, ironía y levedad, para incursionar en territorios ajenos sin temer los severos reproches a que hace referencia Febvre en la cita anterior. Parecería que la nueva y ambigua etiqueta de «novela-testimonio» inventada por Miguel Barnet sirva, al mismo tiempo, como un «escamotage» para eludir la férula del maestro especialista, celoso cuidador de su coto, para transmitir un mensaje considerado «útil» y para amenizar una lectura cuyo propósito es llegar a un vasto público.

Unos historiadores atentos y sensibles como Bloch y Febvre han tenido la osadía de romper barreras, de trabajar en la frontera de disciplinas diferentes y han contribuido al enriquecimiento de las ciencias humanas con los reveladores planteamientos de la historia material, de la historia de los sentimientos, de la historia de las mentalidades, de la microhistoria. Un grupo siempre más numeroso de autores está abriendo el camino a un nuevo género fronterizo (unos, siguiendo a Alfonso Reyes, lo llaman toda-

\footnotetext{
${ }^{2}$ Por todas esas cosas escribo, entrevista a Nora Sosa, Granma, 6 de julio de 1986.

${ }^{3}$ Una sociología literaria para una nueva identidad, entrevista de Alessandra Riccio, Latinoamérica, año III, núms. 5-6 (Roma: 1982), p. 112. La traducción es mía.
} 
vía ancilar; Julio Miranda ${ }^{4}$, más hábilmente a mi modo de ver, lo llama limítrofe), que ya cuenta con un notable corpus de textos y que viene asumido como una exigencia ineludible, un reclamo político y social urgente en América Latina y en Cuba en particular, donde, en más de un caso, un discurso narrativo perfectamente logrado y un hábil montaje hacen que el texto funcione al mismo tiempo como ensayo, como obra literaria y como instrumento didáctico.

¿Quién pierde y quién gana en estas incursiones en territorio ajeno? Pierde el que necesita medir su espacio para tener la seguridad de moverse en un territorio homogéneo y controlable; gana el lector, que disfruta el placer del texto y aprende deleitosamente; gana quien considera que nada humano le es ajeno y quien está acostumbrado a la mezcla, a la contaminación fructuosa, al desorden enriquecedor.

En un país como Cuba, transculturado y sincrético, cuya existencia en la escritura empieza, como en el resto del continente latinoamericano, con diarios de viaje y crónicas de la conquista, es decir, con una literatura testimonial, cuya «literariedad» a estas alturas empieza a ser un hecho aceptado $^{5}$; en un país como Cuba, lo químicamente puro no existe, no puede existir. A la pregunta ¿qué siente un cubano cuando descubre que no existe como etnia original?, Barnet contesta:

El cubano, frente a la evidencia de que no es un pueblo original, siente la necesidad de definirse, de descubrirse a sí mismo, porque de otra forma tendría que resignarse a no ser. De allí le viene la fuerza que lo lleva a no limitarse al nacionalismo, sino a buscar algo más; de allí le viene el interés y el compromiso hacia el Caribe, una zona geográfica donde todos los pueblos son híbridos y creadores. Justamente en el mestizaje de estos pueblos nuevos del Caribe está el germen de una nueva cultura en gestación, que cuando por fin será, será terriblemente fértil ${ }^{6}$.

${ }_{4}$ «El margen que quería señalar corresponde a una amplia corriente de narrativa limítrofe, desde reportajes, apuntes, diarios más o menos novelados, hasta lo llamado por Miguel Barnet "novela-testimonio". Se trata, desde luego, de una región demasiado extensa, demasiado poco formulada teóricamente y difícil de encasillar, pero que está tomando en Cuba un cuerpo a estas alturas ya rico y voluminoso» (Julio E. Miranda, Nueva literatura cubana [Madrid: Cuadernos Taurus, 1971], p. 102).

${ }_{5}$ Baste citar el convincente ensayo de Beatriz Pastor Discurso narrativo de la conquista de América (La Habana: 1983) y el inteligente trabajo del joven hispanista Augusto Guarino La spedizione di Ursúa e la rivolta di Lope de Aguirre (Cagliari: 1965).

${ }^{6}$ Conversando con Miguel Barnet, entrevista de Alessandra Riccio, Latinoamérica, año tercero, núm. 6 (septiembre-diciembre 1982), p. 88. La traducción es mía. 
Sobre Cuba ha pesado, durante siglos, una interdicción implacable: la prohibición de hablar de sí. Siglos de celosa vigilancia del gobierno de Madrid han limitado, por una parte, la adquisición de lecturas externas, y por otra (una mutilación aún más dolorosa), la posibilidad de hablar de sí, de describir su propia geografía, de contar su propia historia. Por un lado, se llegó a prohibir - por peligrosamente antiesclavistas - tanto el Ensayo político sobre la isla de Cuba, de Alejandro de Humboldt, como las novelas $S a b$ y Dos mujeres, de Gertrudis Gómez de Avellaneda, para dar unos ejemplos relativamente recientes, mientras por el otro se prohibía tajantemente a los habitantes hablar de cosas de la isla. Hortensia Pichardo anota:

No se conformó España con dejar en total abandono la enseñanza elemental en sus dominios de América, sino que trató de impedir la expresión del pensamiento de sus hijos y que llegaran hasta ellos las manifestaciones de la cultura de otras partes del mundo, aun de la propia España. Son numerosas las reales disposiciones que imponían restricciones y trabas a los autores que pretendían publicar sus producciones y también a la introducción de libros en América. Comienzan estas leyes restrictivas a mediad is del siglo xvl y perduran durante toda la época colonial... No es extraño q.te estando sujeta la producción del pensamiento a tantas trabas y hasta casi prohibida la lectura, a lo que hay que añadir que los medios de difusión de la cultura -la universidad, los centros de estudios superiores y la imprenta- llegaron más tarde que a otros lugares de América; no es extraño, repetimos, que la producción literaria, sobre todo la histórica, fuera tan limitada en Cuba ${ }^{7}$.

Este vacío secular ha generado una fuerte necesidad de conocer, que empieza a expresarse en coincidencia con las guerras de independencia y que se hace más evidente y explícita a partir de la revolución, cuyas vicisitudes y desarrollo le han otorgado a la Isla la «densidad» que es dado conseguir cuando la historia llega a ser una experiencia vivida por las masas. Esta necesidad se traduce en una espera de textos aptos para hablarle al nuevo lector de la historia, de que se siente partícipe desde una base de verdad y en un lenguaje que le resulte accesible para poder sacar de allí un conocimiento que hasta entonces le había sido negado, y al mismo tiempo estimula al escritor a buscar las huellas de esta participación y a dar testimonio de ella ${ }^{8}$.

${ }^{7}$ Para toda esta materia, véase Hortensia Pichardo, Estudio preliminar, en Nicolás Joseph de Rivera, Descripción de la isla de Cuba (La Habana: 1975), particularmente el capítulo «Leyes para que los americanos ignoren las cosas de América» (pp. 19-29). La noticia sobre Humboldt está en Armando Bayo, Humboldt (La Habana: 1970), p. 113.

${ }^{8}$ Sobre el tema de la política cultural, de los vínculos entre intelectuales y el poder y sobre la literatura nacional-popular, definición que muchos han juzgado infeliz, ha trabajado 
De ahí nace la literatura de campaña, de ahí también la importancia que los textos testimoniales han tenido en el lector cubano, empezando por el más importante de todos, el Diario de José Martí, que se convierte en lectura fundamental incluso para un hombre tan aparentemente distante de este género como José Lezama Lima. Lo que a él le interesa, lo que él juzga fundador para la identidad nacional cubana, es el testimonio que, a través de sus rápidas notas de campaña, Martí deja para los de la «siguiente caravana» ${ }^{9}$. Autor y lector, en Cuba, sienten uno el deber de testimoniar y el otro la necesidad de conocer a través de aquel testimonio su propia realidad, es decir, de conocerse como individuos y como parte de una nacionalidad. Esto le da a la literatura cubana, desde siempre, una fuerte densidad testimonial, muy evidente en escritores como Pablo de la Torriente Brau o como Raúl Roa, quienes se salen decididamente del reportaje o de la nota política en textos como 105 días preso (1931) o La jornada revolucionaria del 30 de septiembre (1937), para limitarme a sólo dos ejemplos.

En 1963, Ernesto «Che» Guevara publica su Pasajes de la guerra revolucionaria, precedido por un breve prólogo donde, en las primeras líneas, ya está formulado el problema fundamental de la narración testimonial tal como se iba entendiendo en Cuba: «Desde hace tiempo estábamos pensado en cómo hacer una historia de nuestra Revolución que englobara todos sus múltiples aspectos y facetas...» Según lo va explicando el «Che», la historia que le interesa narrar no es la Gran Historia, sino «recuerdos

con lucidez Antonio Gramsci en sus Quaderni: «"Estado" significa de modo especial dirección consciente de las grandes multitudes nacionales; por tanto, es necesario entrar en "contacto" sentimental e ideológico con dichas multitudes y, en cierta medida, con simpatía y comprensión de sus necesidades y exigencias (p. 17). La inmediata toma de contacto entre lector y escritor se realiza cuando en el lector la unidad de contenido y forma contiene la premisa de unidad del mundo poético y sentimental; de otra manera, el lector tiene que empezar por traducir la "lengua" del contenido en su propia lengua (p. 27). Es evidente que hay que hablar, para ser precisos, de lucha para "una nueva cultura" y no para "un nuevo arte" (en sentido inmediato). Es posible que tampoco podamos decir, si queremos ser exactos, que se lucha para un nuevo contenido del arte, porque eso no puede ser pensado de manera abstracta, separado de la forma [...]. Hay que hablar de lucha por una nueva cultura, es decir, por una nueva vida moral que debe estar íntimamente unida a una nueva intuición de la vida, hasta llegar a ser un nuevo modo de sentir y de ver la realidad y, por consiguiente, un mundo intimamente connotado con los "artistas posibles" y con las "obras de arte posibles"》(p. 8). Cito por la edición antológica: Antonio Gramsci, Letteratura e vita nazionale (Roma: Editori Riuniti, 1987). La traducción es mía.

9 José Lezama Lima, Paralelos: la poesía y la pintura en Cuba, en La cantidad hechizada, Obras completas, tomo II (México: 1975), pp. 366-367. Sobre el interés de Lezama hacia el Diario, véase Alessandra Riccio, «El Diario de Martí en José Lezama Lima», Unión, núm. 2 (La Habana: 1985). 
personales de los ataques, combates, escaramuzas y batallas en que intervinimos», $y$, sin embargo, parece que a partir de estos acontecimientos menores, individuales, marginales, puede y debe dibujarse un cuadro nuevo de la historia donde cada uno tiene la posibilidad de contar, desde su propio punto de vista, desde su personal experiencia, «hechos que ya pertenecen, incluso, a la historia de América». Según Guevara, hay que hacer «asequible a todos los participantes en la gesta revolucionaria la tarea de narrarla», y pone sólo una condición, que es una condición fundamental:

Sólo pedimos que sea estrictamente veraz el narrador... que después de escribir algunas cuartillas en la forma en que cada uno lo pueda, según su educación y su disposición, se haga una crítica lo más seria posible para quitar de allí toda palabra que no se refiera a un hecho estrictamente cierto o en cuya certeza no tenga el autor una plena confianza ${ }^{10}$.

Diríase que el «Che» está estableciendo un pacto que obligue al narrador a contar su estricta verdad y al lector a creerle. Estamos todavía en el ámbito de lo puramente testimonial; «Che» está preocupado por la memoria histórica y busca y ofrece testimonios de la epopeya vivida; pide que se haga el esfuerzo de narrarla, y la invitación está dirigida a todos los supervivientes, y, sin embargo, descarta cualquier preocupación «literaria», no le interesa el «modo» como se cuenta. Los lectores sabemos muy bien que, al ofrecer el testimonio de algunos momentos de la guerra revolucionaria, Guevara supo montar su relato con un gran talento y eficacia, tanto que uno de los «pasajes» entró pronto a formar parte de antologías de cuentos bajo el título de El cachorro asesinado. Por otra parte, la invitación a contar cada uno según su educación y sus posibilidades puede surgir de la confianza de que el argumento mismo, su misma realidad, hagan que la mise en pages dé resultados que satisfagan el horizonte de espera del lector a quien está dirigida la narración, como acontece en el caso del «Che».

Sobre ese problema ha reflexionado Italo Calvino al prologar, muchos años después, su primer libro, Il sentiero dei nidi di ragno, escrito al calor de los recuerdos de la guerra recién acabada:

Más que como una obra mía, lo leo como un libro nacido anónimamente del clima general de una época, de una tensión moral... El hecho de haber salido de una experiencia - guerra, guerra civil- que no había ahorrado a nadie, establecía una inmediatez de comunicación entre el escritor y su público: estábamos cara a cara, a la par, cargados de historias por contar,

${ }^{10}$ Ennesto «Che» Guevara, Pasajes de la guerra revolucionaria (La Habana: Ediciones Unión, 1963), pp. 5-6. 
cada uno tenía la suya propia, cada uno había vivido vidas irregulares, dramáticas aventuras, cada uno le quitaba la palabra de la boca al otro... Durante la guerra «partisana» las historias recién vividas se transformaban y transfiguraban en historias contadas durante la noche en torno al fuego, adquirían ya un estilo, un lenguaje, un humor como de bravuconada, una búsqueda de efectos...

En este ámbito denso de protagonistas directos e indirectos, empujados a narrar por la fuerza misma de los acontecimientos que los han visto partícipes, un escritor como Italo Calvino confiesa:

Algunos de mis cuentos, algunas páginas de esta novela, tienen en su origen esta tradición oral recién nacida, en los hechos, en el lenguaje ".

Porque cuando da la casualidad que el narrador, además de testimonio de los eventos narrados, es también escritor, surge el problema «consciente» de cómo se mete en la página el material narrable, un problema que el «Che» había resuelto en la práctica, pero no había elaborado en la teoría ni lo había esbozado siquiera como problema, quizá por entender, como Calvino, que hay momentos en que los elementos extraliterarios se presentan de forma tan maciza e indiscutible que parecen datos de la naturaleza.

Resumiendo, en la formación de una identidad cultural cubana, junto con otras componentes, lo testimonial ha ido sedimentando una tradición que se apoya en la necesidad de conocerse, una necesidad transitiva que pasa del narrador al lector de una forma inmediata y sencilla, sin que el lector pretenda más que la verdad de lo narrado y sin que el narrador se sienta obligado más que a ofrecer su verdad en el común y recíproco intento de estructurar una memoria y de ofrecer elementos de conocimiento. Sin embargo, este sencillo pacto testimonial entre escritor y lector se basa sobre un acto solemne de adquisición de responsabilidad del autor, quien,

1 Italo Calvino, Prefazione a Il sentiero dei nidi di ragno (Turín: Einaudi, 1972), páginas 7-24. La novela, publicada en 1947, fue una de las primeras muestras y de las mejores de lo que se llamó «neorrealismo» italiano; en 1964, cuando ya esa corriente sufría los polémicos ataques que investían al «realismo» en todos sus aspectos, el autor escribe el largo prefacio que cito; acudo a Calvino porque, en su reflexión, escrita diecisiete años después del libro, cuando ya su camino literario derivaba hacia otros intereses, no sólo no reniega de su novela tan densamente testimonial y «realista», sino que defiende las razones que lo impulsaron a escribirla: «Porque quien hoy recuerda al "neorrealismo" sobre todo como una contaminación o coartación padecida por la literatura por razones extraliterarias, cambia los términos de la cuestión; en realidad, los elementos extraliterarios estaban allá tan macizos e indiscutibles que parecían un dato de la naturaleza; nos parecía que todo el problema fuera de tipo poético, cómo transformar en obra literaria aquel mundo que para nosotros era el mundo.» 
al escoger la palabra escrita, tiene conciencia de que se está comprometiendo frente a su sociedad, y entiende que «lo que está escrito adquiere un valor moral práctico que trasciende en mucho el solo hecho de estar escrito, que en la práctica es un puro hecho material»" ${ }^{12}$.

En 1970, Casa de las Américas decide incluir en su premio anual el género Testimonio; en el mismo año dedica el número 62 (septiembre-octubre de 1970) de su revista a la Gran Zafra, valiéndose de la colaboración de ensayistas, novelistas, poetas, en la gran mayoría cubanos, quienes ofrecen su testimonio, en las formas más heterogéneas, sobre el grandioso esfuerzo colectivo de la zafra de los diez millones, que empeñó a la casi totalidad de la población cubana.

Evidentemente, aquella institución cultural juzgó, en aquel año, que había que poner de relieve la existencia de un género, si no nuevo, que iba cobrando siempre más vigencia y que iba siendo practicado por una capa siempre más amplia de escritores, profesionales o no. Al premio Testimonio, en su primera convocatoria, participaron diecinueve obras procedentes de toda América Latina. El jurado estaba integrado por verdaderas autoridades en este género incipiente: el mexicano Ricardo Pozas, autor del sorprendente y fundador Juan Pérez Jolote, que constituye un texto fundamental en las letras latinoamericanas; el argentino Rodolfo Walsh, a quien debemos su desgarrador libro Operación Masacre, descrito, a falta de otra definición, como un «relato-documento» en una reseña que figura en el mismo número de la revista, y el cubano Raúl Roa, que ya hemos señalado entre los precursores del género. Dando a conocer al vencedor (la uruguaya María Esther Gilio, con La guerrilla tupamara), el jurado señalaba «que la incorporación de este género al premio Casa de las Américas ha sido un éxito por la alta calidad promedio de las obras», y añadía que «el alto nivel obligó al jurado a sopesar minuciosamente los méritos literarios, la actualidad del tema y la trascendencia política y social de los trabajos», y esto a pesar de la motivación bastante genérica y escasamente definitoria que figura en las «bases» institutivas, que hablan de «un libro donde se documenta, de fuente directa, un aspecto de la realidad latinoamericana actual».

El jurado, cuyos integrantes habían dado prueba de los resultados excelentes a que puede llegar el género, hace constar su empeño de «sopesar minuciosamente los méritos literarios» entre otras características más pro-

12 Antonio Gramsci, Lettere dal carcere, vol. II (Roma: 1988), p. 191. Está en la carta a Tania del 27 de febrero de 1933. 
pias del testimonio, como pueden ser la actualidad del tema o su trascendencia política y social.

Sucedía que en 1966 Miguel Barnet había publicado Biografía de un cimarrón, entonces subtitulado como relato étnico, y en 1969, Canción de Rachel, acompañado por una conferencia, «La novela testimonio: socioliteratura», que luego pasó a integrar en forma de prólogo la edición barcelonesa de 1970. Es decir, que en 1970 el problema «literario» del testimonio era ya un problema discutido y teorizado en Cuba.

En el transcurso de tiempo que media entre el primero y el segundo de sus libros, Miguel Barnet ha sido capaz de superar aquella forma de timidez que le había hecho declarar en su «Introducción» al Cimarrón: «Sabemos que poner a hablar a un informante es, en cierta medida, hacer literatura. Pero no intentamos nosotros crear un documento literario, una novela» ${ }^{13}$. Ya en la conferencia con que presenta su segunda obra, Barnet se mete de lleno en la médula del problema: Rachel no es el Cimarrón y lo de «relato etnográfico», aceptable en el caso del viejo esclavo, resultaría dudoso en el caso de la caprichosa ex vedette de la Alhambra. Entonces, ¿Cómo clasificar el obsesivo monólogo de Rachel, sus recuerdos, su memoria tratando de hacer revivir un mundo perdido? La reflexión de Barnet se desliza entre las definiciones de «relato etnográfico y novela realidad» para llegar a la de «novela-testimonio: un desentrañamiento de la realidad, tomando los hechos principales, los que más han afectado la sensibilidad de un pueblo y describiéndolos por boca de uno de sus protagonistas más idóneos» ${ }^{14}$. En la novela-testimonio, según Barnet, es indispensable que el escrito: haga un uso discreto de su yo, porque «en esa despersonalización es en la que el arte se aproxima a la ciencia» y para que esta despersonalización le haga decir al autor, junto con su informante, "yo soy la época». Según Barnet, ésta es «una premisa inviolable: la flecha en el blanco». A partir de esta identificación, el escritor está en condiciones de entregarle al lector

un mito que le resulte provechoso, útil, desde cuyo modelo puede categorizar. Este modelo, de más está decirlo, debe ser relativo o ambiguo; no puede ser un patrón estático y definitivo, sino sólo un punto de partida. Eso he querido que sean Cimarrón y Rachel, puntos de partida para conocer un medio, una época.

${ }^{13}$ Miguel Barnet, Biografía de un cimarrón (La Habana: Academia de Ciencias de Cuba, 1966), p. 9.

14 Miguel Barnet, «La novela testimonio: socio-literatura», ahora en La fuente viva (La Habana: Editorial Letras Cubanas, 1983), p. 23. 
El fenómeno histórico engaña, ofrece una parte de la realidad, y el autor, que Barnet acertadamente llama «el gestor de la novela-testimonio», tiene que revelar la «esencia de una apariencia» haciendo uso de un lenguaje comunicativo quintaesenciado, más cercano de la naturaleza que de la caricatura. Así será posible recobrar «el eslabón perdido» de la tradición de un país recuperando la historia de «la gente sin historia» ${ }^{15}$.

Diez años después, al reseñar La fiesta de los tiburones, de Reynaldo González, el mismo Barnet aclara:

El autor ha sabido escoger sus personajes, les ha captado el decir, se ha identificado con ellos en una fusión plena, ha podido, pues, orientarlos hacia los resultados buscados sin necesidad de mutilaciones, sin conceder demasiado tampoco y sí con rigor científico y malicia literaria... Hay creación en este libro. Está la presencia del artista en la selección de los textos y en su ensamblaje. Sin esa presencia hubiera quedado simplemente en el mero repertorio o en la recolección de los testimonio. Pero al autor le salva la imaginación. Y no sólo la imaginación artística, sino la imaginación sociológica e histórica, sin la cual todo material sobre estas disciplinas es incompleto, queda manco ${ }^{16}$.

En las líneas citadas anteriormente ha desaparecido la definición de gestor, sustituida, tout-court, por las de autor y artista; al cabo de diez años ya la idea de novela-testimonio se ha hecho más clara y concreta, por lo menos en la mente de su creador, Miguel Barnet, quien sigue usando esta definición para algo que no está teóricamente explicado y que, sin embargo, existe en el gusto del lector, en la intención del autor e incluso en el reconocimiento de parte de la crítica. Actualmente, la novela-testimonio es una fuerte y vital realidad de las letras cubanas, nutrida, entre otras, con las obras de Víctor Casaus, Raúl González de Cascorro, Reynaldo González, Nancy Morejón y el mismo Barnet, quien, con Gallego (1981) y La vida real (1984), sigue contribuyendo notablemente a fundamentar una nueva tradición literaria ${ }^{17}$.

Del testimonio, un género todavía sin clasificar, hemos pasado, pues, a la novela-testimonio, un híbrido extraño con que, a falta de mejor definición, Barnet quiso afirmar - autoafirmar - que la narrativa testimonial le pertenece a la literatura ${ }^{18}$. Trataré de explicar por qué le atribuyo a la

${ }^{15}$ Ibid., passim.

16 Miguel Barnet, ibid.,pp. 94-95.

${ }_{17}$ Pienso, en particular, en Girón en la memoria, de V. Casaus (1970); Lengua de pájaro, de Nancy Morejón y Carmen Gonce (1971); Aqui se habla de combatientes y bandidos, de R. González de Cascorro (1975); La fiesta de los tiburones, de R. González (1979), y del mismo autor, Llorar es un placer, de próxima publicación.

${ }^{18}$ Declara Miguel Barnet en «La novela testimonio: socio-literatura», cit., p. 20: «Es 
provocación de Miguel Barnet, a su invención de este mots-valise ${ }^{19}$, un intento de acelerar el deslizamiento de un género maltratado, ancilar, limítrofe, hacia el campo de la literatura, es decir, hacia la representación, el conseguimiento de una imagen que reviva y actualice la(s) historia(s).

En orden de tiempo, los últimos productos de la escritura que han pujado para conseguir su estatuto literario son, me parece, la autobiografía y el testimonio. Philippe Lejeune ha estudiado largamente el problema de la autobiografía, llegando a algunas conclusiones interesantes. Un género literario no existe en sí; al contrario, va formando un código implícito propio que puede ser recibido y clasificado por el lector; en el caso en que el género tuviera ya un estatuto, pero externo a la literatura, como es el de la autobiografía (y del testimonio), es un deber del crítico tratar de contribuir al cambio de estatuto para promoverlo al campo de la literatura. Ahora, la crítica suele descartar todo lo que le pertenece a la historia (la relatividad y la variabilidad) para obedecer a su deseo normativo y teórico de buscar invariantes que permitan «découvrir les lois de fonctionnement des systèmes historiques des genres» ${ }^{20}$; aquí está la gran resistencia que la crítica ofrece a géneros tan contingentes y contiguos a la historia como son la autobiografía (y el testimonio), a los cuales el público lector reconoce literariedad mucho antes que la crítica logre dar su aval teórico motivado. Sobre estas premisas, Lejeune salva los obstáculos gracias a la teoría de la recepción, y llamando al campo del lector, llega a formular la teoría del «pacto». Para aceptar la tesis del «pacto» hay que reconocerle al lector el papel fundamental de ser él quien pone en marcha, hace funcionar el texto y, por tanto, reconocerle la función de contraparte en el mecanismo de recepción del texto.

Digamos, pues, que autor y lector establecen un «pacto», donde quien escribe declara, «atestigua», que lo que está narrando es fruto de un conocimiento directo o indirecto de una historia y de unos acontecimientos que contribuyen a la esfera del conocimiento del lector y que atañen a una realidad que lo incluye de una forma o de otra. El lector, por su parte,

ocioso que trate de explicar que apelé al opresivo término de novela por no hallar otra nomenclatura más asequïble y porque la novela es un vocablo familiar a todos. Tan familiar, que a cada rato nos está jugando una mala pasada, como ahora, por supuesto, que yo la antepongo a otro término no menos engañoso, el de testimonio.»

19 Creador de esta palabra es el francés Alain Finkielkraut, Ralentir: Mots-valise (París: Gallimard, 1979). El término indicaría la unión de dos palabras que, aun manteniendo cada una su significado original, llegan a indicar una tercera cosa diferente.

${ }^{20}$ Philippe Lejeune, «Autobiographie et histoire littéraire», en Revue d'histoire littéraire de la France, núm. 6 (noviembre-diciembre 1975), p. 920. 
acepta el pacto, pero mantiene su vigilancia sobre el texto para controlar que el pacto sea respetado.

Esto obliga al autor-gestor del relato a usar su material y a comportarse frente al lector exactamente como frente a un tribunal encargado de establecer la verdad de los hechos que se narran, es decir, que en el momento en que el autor se pone a relatar hechos con «intención» testimonial asume toda la responsabilidad propia de quien ofrece su versión de hechos vividos directamente por él o conocidos gracias a otras fuentes de información que él juzgue absolutamente fidedignas. Estableciendo el pacto, el autor no solamente asume su responsabilidad, su compromiso con la historia y con la sociedad, sino que declara explícitamente que elige el riesgo de la claridad del pacto, que no se va a refugiar en el regazo de la «ficción», que habla para que le oigan y que su «verdad testimoniada» responde a su sentido de responsabilidad frente al lector. Este es el motivo de que autores como Jorge Narváez puedan definir el testimonio como una «narrativa de no ficción», que tiene "la virtud histórico-literaria de insertarse en el proceso de producción de sentido del discurso literario latino- americano" ${ }^{21}$. Por otra parte, Renato Prada Oropeza, en un denso artículo que es una de las contribuciones más fundamentadas para un cambio de estatuto del género, para su «promoción» al campo de la literatura, intuye la necesidad de reconocer el «pacto testimonial» cuando da la siguiente definición de lo que él llama «discurso testimonio»:

Es un mensaje verbal (preferentemente escrito para su divulgación masiva, aunque su origen sea oral) cuya intención explícita es la de brindar una prueba, justificación o comprobación de la certeza o verdad de un hecho social previo, interpretación garantizada por el emisor del discurso al declararse «actor»o testigo (mediato o inmediato) de los acontecimientos que narra ${ }^{22}$.

$\mathrm{Al}$ reflexionar sobre el género testimonio, René Jara recuerda que en la literatura latinoamericana estuvo siempre presente una «funcionalidad ética y política de la imaginación discursiva», que estaría representada por los cronistas de Indias, en el romanticismo político de Sarmiento, Lastarria y Echeverría, en la gran producción naturalista, en el indigenismo e incluso en el neorrealismo de los años cuarenta, «para culminar en la vertiente testimonial», a propósito del cual Jara anota:

${ }^{21}$ Jorge Narváez, «El testimonio 1972-1982. Transformaciones en el sistema literario», en autores varios, Testimonio y literatura (Minneapolis, Minnesota: 1986), pp. 235-279.

${ }^{22}$ Renato Prada Oropeza, «De lo testimonial al testimonio. Notas para un deslinde del discurso-testimonio», en autores varios, Testimonio y literatura, cit., pp. 7-21. El subrayado es mío. 
El narrador es sólo una parte de la realidad; no es su artífice ni es mero relator. Esto refuerza el carácter del imaginario testimonial: los operadores textuales son operadores históricos, los contenidos semánticos descansan en su literalidad, la cosa real es, aporéticamente, su imagen ${ }^{23}$.

El testimonio, basado sobre un pacto entre lector y autor, contiene en sí la posibilidad de llegar a la representación, a la quintaesencia, a la imagen poética partiendo de hechos reales y concretos, caminando del brazo de la historia, superando su carácter évenèmentiel y desmintiendo a Aristóteles: la provocadora novela-testimonio reivindica para la variabilidad y relatividad de los hechos particulares, para la narración de la gente sin historia, un estatuto poético.

Franco Rella, en un ensayo sobre «El pensamiento de la narración», plantea una interesante hipótesis: cuando Platón, en un gigantesco esfuerzo intelectual para racionalizar al mundo, llega a afirmar que las formas de la verdad son inmutables, le niega derecho de existencia a la phronesis, un don de Zeus que abre los caminos de la sabiduría a los mortales, al establecer que phronein (conocer) significa tener pasiones (pathein) y que esto permite a los hombres, que lo quieran o no, alcanzar la sabiduría (Esquilo, Agamenón, vv. 176 y sigs.). El arte constituye, según Rella, el desarrollo más alto del «conocer con pasión»; el hecho estético, lo «inefable» del arte es indescriptible e indecible fuera del reconocimiento de que la phronesis constituye un pensamiento y que, gracias a ella, es posible llegar al conocimiento a través de la imagen. El pensamiento de la narración, dice Rella, es a-tópico frente al concepto habitual de real y de realidad, no tiene y no quiere un lugar determinado, se coloca en un «dondequiera» que trastrueca el orden acostumbrado. El pensamiento de la narración, por tanto, es el único pensamiento que no se impone como objetivo el dominio sobre el otro, sino más bien «la experiencia del otro». Es por esto que Rella juzga fatua la distinción entre gran literatura y literatura menor: lo que importa es reconocer que la experiencia artística y literaria es, ha sido y puede ser una forma de pensar del mundo, externa a la dialéctica del poder, que el pensamiento narrativo puede ser asumido como un pensamiento ético, y no solamente estético, a pesar de ser de por sí un pensamiento heterodoxo por su rechazo a transformar su saber en poder. El pensamiento de la narración no quiere un lugar porque no puede renunciar a alguno, no sacraliza una imagen porque para él todas son sagradas, no puede descartar una experiencia porque necesita de todas las experiencias. No responde a interrogaciones: al contrario, entrelaza las preguntas y escoge la ambigüedad; es por esto que ningún producto de

\footnotetext{
${ }^{23}$ René Jara, «Prólogo», en autores varios, Testimonio y literatura, cit., pp.1- 6.
} 
este pensamiento, ninguna obra, es prescindible. En el campo del pensamiento de la narración es imposible moverse como en filosofía, donde se puede invalidar una teoría: aquí, dice Rella, «el desarrollo de la novela después de Cervantes no está en grado de borrar una sola línea de Cervantes» ${ }^{24}$.

Para concluir: el testimonio empieza en América Latina como una narrativa de «zona» con los relatos de crónica, es decir, con las primeras manifestaciones escritas referidas al continente, se mantiene vivo durante cinco siglos «en sí̀ y «por sí», cobra un sentido más amplio a finales del siglo pasado y se afirma en nuestro siglo con el deslinde de las fronteras habituales de la crónica, el reportaje, el relato testimonial, estableciendo un pacto con el lector que lo acerca siempre más al campo de la literatura gracias a la imaginación y al montaje con que el autor se enfrenta a su material. Al borde de los años setenta, Cuba, cuya historia ha adquirido una densidad colectiva inédita, recoge el desafío del género testimonial por boca de Miguel Barnet y lo lanza directamente al ámbito literario con la provocadora definición de novela-testimonio, que subraya, por una parte, la libertad que el autor se otorga para «imaginar, relatar y organizar» su material, y por otra, su asunción de responsabilidad frente al lector sobre la verdad del material narrado, no sólo por una mera actitud ético-intelectual respecto a la urgencia de demanda de una sociedad en revolución, sino también para contribuir al conocimiento, para traducir la cosa real en su imagen siviéndose del pensamiento de la narración, que consigue decir lo inefable artístico atribuyéndole propiedades cognoscitivas. Según palabras de Barnet,

la novela-testimonio ha contribuido en Cuba a la información, convirtiéndose en soporte totalizador de la misma, ha enriquecido la visión de la realidad histórica y social y ha devuelto a las masas el sentido de identidad, sirviendo a la vez de espejo cóncavo y retrovisor ${ }^{25}$.

${ }^{24}$ Franco Rella, «Il pensiero della narrazione», en Belfagor, año XLIII, núm. 1 (31 de enero de 1988), pp. 92-96.

${ }^{25}$ Miguel Barnet, «Testimonio y comunicación: una vía hacia la identidad», en La fuente viva, cit., p. 50. 